\title{
SEISMIC VULNERABILITY OF CYLINDRICAL STEEL LIQUID STORAGE TANKS FOR AN OIL INDUSTRY PLANT
}

\author{
Mohsen YAZDANIAN ${ }^{1,}$, , Mahmoud MASHAL ${ }^{2}$, Seyed Vahid RAZAVI ${ }^{3}$ \\ ${ }^{1}$ Young Researchers and Elite Club, Ahvaz Branch, Islamic Azad University, Ahvaz, Iran \\ ${ }^{2}$ Department of Irrigation Engineering, Aburaihan Campus, Tehran University, Tehran, Iran \\ ${ }^{3}$ Department of Civil Engineering, Jundi-Shapur University of Technology, Dezful, Iran
}

\begin{abstract}
Liquid storage tanks have a pivotal role in supplying of different type of liquids. In addition, they are widely used in disparate industrial plants. Failure of these structures has dire consequences and detrimental impacts on economy of countries. Hence, in this study, the seismic behavior of these structures with an emphasis on their seismic vulnerability under different conditions is analyzed. For this purpose, an oil industry plant in the south of Iran is considered and five different tanks with different dimension are chosen. Three significant vulnerability parameters which are usually taken into account for evaluation of tanks are investigated. These criterions include: 1) Sliding, 2) Elasto-Plastic buckling (Elephant foot buckling), 3) Tank roof damage. Four integral analyses including static, modal, response spectrum and time history is utilized. In time history analyses, multiple records are selected to conduct a comprehensive evaluation of system. Finally, the results show that tanks are safe under Elephant foot buckling fragility parameter. However, this is not always the case for tank's roof vulnerability and sliding. In addition to this, tanks with higher diameter have witnessed higher wave height and are possible to be in danger for tank's roof vulnerability, while these tanks have shown an appropriate behavior against sliding.
\end{abstract}

Keywords: Storage tanks, Seismic, Fragility, Dynamic

\section{INTRODUCTION}

Liquid storage tanks, as lifeline and strategically vital structures are usually used in different places. Cylindrical storage tanks are greatly used for their simple design, cost efficiency, and very thin perimeter walls [1]. It is obvious that cylindrical tanks in refineries and chemical plants are generally used for storage of hazardous chemicals such as oil. A small accident may pose economical loss and sometimes lead to interruption in production [2]. One example of this is damages caused by the 1964 Niigata earthquake, with a reported extensive uncontrolled fire eruption in petroleum tanks and the burning of 286 houses in the adjacent area [3]. The seismic behavior of storage tanks is a very complex subject matter and fluid- structure interaction and variation in liquid weight are also two important issues that have to be taken into account in tank analysis modeling [4].

The most universally-used analytical model is the one developed by Housner [5]. The hydrodynamic pressure in Housner's model is separated into impulsive and convective components using lumped mass for rigid tanks. The results of proposed model have been adopted with some changes in most of the existing codes and standards. For the first time, using finite element (FE) method as a tool for estimating the seismic response of a cylindrical liquid storage tank is suggested by Edwards [6]. The proposed model in FE technique was capable of estimating the coupled interaction between the elastic tank perimeter wall and the stored liquid. Further research on the seismic and dynamic behaviour of both cylindrical and rectangular tanks can be extensively found in the literature review [2, 4, 6 and 7]. A more detailed look at the literature review makes it clear that the majority of conducted studies in this field have used FE method as their main method to analyse the structures. 
Although many investigations has been conducted on dynamic behavior of liquid storage tanks, some studies related to seismic fragility of storage tanks and also field observations during past earthquakes can be found barely in the literature review. James and Raba [7] used different structural models to study the dynamic behavior of liquid tanks. They utilized FE method to assess stresses and deformations during an earthquake. Brown et al [8] and Haroun [9] investigated the damage observations on cylindrical tanks along the 1994 Northridge earthquake and to the 1979 Imperial Valley earthquake. Their study focused on field observation and showed that tanks are quite vulnerable during severe earthquakes. Gupta and Hutchinson [10] studied the effects of wall flexibility on the dynamic response of liquid storage tanks and indicated that for both shallow and deep tanks frequencies decrease with reduction of wall thickness. Kieselbach [11] investigated large cylindrical tanks and observed environmental damage and economic loss due to the lack of attention to the tank's design. Dogangun et al [12] studied failure and damage of silos. They discussed their causes. Damage and failure of silos in different regions of the world are presented and discussed in their research. Emanuele Brunesi et al [13] investigated the dynamic response of cylindrical storage tanks, in light of field observations collected in the aftermath of the May 2012 earthquakes in Northern, Italy. They observed that the vast majority of the cylindrical tanks were damaged excessively. Hosseinzadeh et al [14] developed different cylindrical tanks using FE software and then compared the results obtained from FE software with those obtained from the American Petroleum Institute (API) standard. They focused mainly on the vulnerability factors including base shear, elephant buckling and stresses. They concluded that there is a similarity between the results obtained from FE software and API standard. Buratti and Tavano [15] studied the dynamic buckling and seismic fragility of anchored cylindrical tanks using added mass technique. They used time history method regarding the case study structure under different records of earthquake to identify the critical buckling loads. Colombo and Almazan [16] assessed the efficiency of a specific energy dissipation procedure in two cylindrical tanks including slender and broad tanks by using the seismic reliability method.

Usually setting up a model to show the behavior of liquid storage tanks is always a controversial issue. A large number of approaches have been suggested in the literature, for example, analytical approaches [17], finite element method (FEM) models [18- 23], Boundary Element Method (BEM)-FEM coupled models [24], and smoothed particle hydrodynamics [25, 26]. In the present paper, FEM is used for liquid and tanks modeling because it shows a good compromise between accuracy and computational cost. It should be noted that ANSYS [27] as a general-purpose computer code is utilized to perform analyses.

Some research has been conducted on steel cylindrical tanks, although there are a number of evidences that these types of tanks are vulnerable against recurrence of severe earthquakes. Recent studies have generally failed to focus on the main reason why these structures experience an eruption during severe earthquakes. By far, the most significant reason in regard to failure of storage tanks are categorized in three disparate failure modes: 1) Sliding, 2) Elasto-Plastic buckling (Elephant foot buckling), 3) Tank roof damage. As a result, in this paper these modes of failure are widely debated and for this purpose, four different analyses including static, modal, response spectrum and time history are conducted to consider the entire possible situation. All the tanks geometry and detail are chosen from a constructed oil industry situated in the south of Iran. One of the distinct advantages of this study over the other papers in this field of area is to do with the inclusion of three earthquake's components (longitude, transverse, and vertical) into analytical considerations. Although it makes the solution of the solver quite complicated, it enhances certain aspects of paper in terms of innovation and validity. In this case, it cannot be denied that the most prominent matter is the realistic and validity. It is worthwhile to note that three components of the ground motions were subjected to analytical models to do this integral breakthrough and also be more precise. This is an important issue and many studies have failed to consider this significant parameter as can be seen from the content of the published literature materials. A further highlighted consideration in this paper is related to selection of ground motions; this paper has a focus on multiple ground motions to predict how a tank will be acted under a severe earthquake. 


\section{CASE STUDY MODELING}

In this study, five cylindrical tanks with different height to diameter $\left(\frac{H}{D}\right)$ ratios and volume have been chosen to study on the effect of height to diameter ratios in seismic behavior of tanks. Mechanical properties of fluid and tank as an input to the model are shown in Table 1. Furthermore, Table 2 illustrates the geometric characteristics of tanks. The tanks' dimensions are selected so that all possible ratios of height to diameter are covered. The same freeboard is considered for each tank. Furthermore, the same wall material and the same fluid were considered for the tanks. In addition, the thicknesses of tanks are considered to be the same in all tanks.

Table 1. Mechanical properties of Fluid and Tank

\begin{tabular}{ccccc}
\hline $\begin{array}{c}\text { Materials } \\
\text { properties }\end{array}$ & Density $\left(\mathbf{k g} / \mathbf{m}^{\mathbf{3}}\right)$ & Poisson's ratio & $\begin{array}{c}\text { Young's modulus } \\
(\mathbf{G P a})\end{array}$ & $\begin{array}{c}\text { Bulk modulus } \\
(\mathbf{G P a})\end{array}$ \\
\hline Steel & 7850 & 0.3 & 210 & - \\
\hline Fluid (water) & 1000 & - & - & 2.07 \\
\hline
\end{tabular}

Table 2. The geometric characteristics of the studied tanks to investigate the impact of $\frac{H}{D}$

\begin{tabular}{ccccc}
\hline Tank No & Height $(\mathbf{m})$ & Diameter $(\mathbf{m})$ & $\frac{H}{D}$ & $\begin{array}{c}\text { Shell thickness range } \\
(\mathbf{m m})\end{array}$ \\
\hline 1 & 6 & 12 & 0.5 & $8-12$ \\
\hline 2 & 9.5 & 12 & 0.8 & $8-12$ \\
\hline 3 & 12 & 12 & 1 & $8-12$ \\
\hline 4 & 12 & 9.6 & 1.25 & $8-12$ \\
\hline 5 & 12 & 6 & 2 & $8-12$ \\
\hline
\end{tabular}

\section{RESULTS AND DISCUSSION}

Several types of analysis i.e. static, modal, response spectrum and time history are performed. Figure 1 shows a schematic view of modeled Tank No. 1 in two disparate conditions. For a start, all the five modeled tanks are considered to be under static condition. It should be noted that this analysis is usually done to have a clear understanding of the validity of tanks which are modeled, and also it provides a basic understanding of the response of the tanks to internal pressure. In static analysis, tanks were analyzed based on their weight and the hydrostatic pressure of internal fluid. This analysis can be used in compound loading. The generated hydrostatic pressure may pose tensile stresses in the tank wall. Prior to the time history and response spectrum analysis, the modal properties of the tanks are investigated. In particular, the fundamental frequencies of tanks, impulsive and convective frequencies are obtained and investigated in depth. This is an appealing analysis as can be used not only for validation but also is a starting point for response spectrum analysis. It is worthwhile to note that without modal analysis, users can not combine modes for response spectrum analysis. During the modal analysis, the Block Lunczos method is used as the mode extraction method. In this method, users can easily specify how many modes they need to be extracted. It should be noted that the whole FE system has countless degree freedom and in the modal analysis, user can obtain frequency as many as number of degree freedom that the system has. Thus, determination of a range for these frequencies is a quite imperative task.

After modal analysis and determination of fundamental frequencies of tanks, response spectrum analysis is performed. Response-spectrum analysis is a linear-dynamic statistical analysis method which measures the contribution from each natural mode of vibration to indicate the likely maximum seismic response of an essentially elastic structure. For this purpose, three component site design spectrum for 
area soil with moderate earthquake hazard has been selected. The produced spectrum is determined by different factors such as earthquake hazard of region and soil type. Iranian Earthquake code [28] is used to determine these characteristics. Finally, time history analysis has been done and for this purpose, three components of earthquake records of Tabas, Kobe and Cape Mendocino have been applied to tanks with multiple $\frac{H}{D}$ proportions. It should be noted that all the records are scaled according to Iranian Earthquake code [28]. Moreover, all three records have a constant time interval of 0.02s. A more detailed look at the records reveals that records have different peak ground acceleration (PGA). This is due to the fact that authors had a tendency to control structures under different excitations. The PGA of Tabas, cobe, and Cape Mendocino is $0.81 \mathrm{~g}, 0.71 \mathrm{~g}$ and $0.59 \mathrm{~g}$ respectively. Figure 2 shows the horizontal component ground motion of three applied records. In addition, more details in regard to selected ground motion records can be seen in the Table 3 .

As stated in many researches on structural dynamics, the equations of motion for a multi degree of freedom system subjected to dynamic forces can be presented in the following form [29]:

$$
[M]\{\ddot{u}\}+[C]\{\dot{u}\}+[K]\{u\}=\left\{F^{a}\right\}
$$

In which $[M],[C]$ and $[K]$ are mass, damping, and stiffness matrices, respectively. $\{u\},\{\dot{u}\}$ and $\{\ddot{u}\}$ are displacement, velocity, and acceleration vectors. $\left\{F^{a}\right\}$ symbolizes the applied load vector. $[C]$ is the matrix representing damping in fluid. ANSYS as a FE software is used to solve the above mentioned equation.

Table 3. Ground motion records specification

\begin{tabular}{ccccccc}
\hline $\begin{array}{c}\text { Records } \\
\text { (Station) }\end{array}$ & Magnitude & $\begin{array}{c}\text { Epicentral } \\
\text { dis }(\mathrm{km})\end{array}$ & $\begin{array}{c}\text { Duration } \\
(\mathrm{s})\end{array}$ & Time step (s) & PGA (g) & $\begin{array}{c}\text { PGV } \\
(\mathrm{cm} / \mathrm{s})\end{array}$ \\
\hline $\begin{array}{c}\text { Tabas, Iran } \\
\text { 1978-09-16 }\end{array}$ & 7.35 & 55.24 & 35 & 0.02 & 0.81 & 98.20 \\
\hline $\begin{array}{c}\text { Kobe, Japan } \\
\text { 1995-01-16 }\end{array}$ & 6.90 & 18.27 & 48 & 0.02 & 0.71 & 77.83 \\
\hline $\begin{array}{c}\text { Cape } \\
\text { Mendocino }\end{array}$ & 7.1 & 4 & 36 & 0.02 & 0.59 & 24.5 \\
1992-04-25 & & & & & & \\
\hline
\end{tabular}
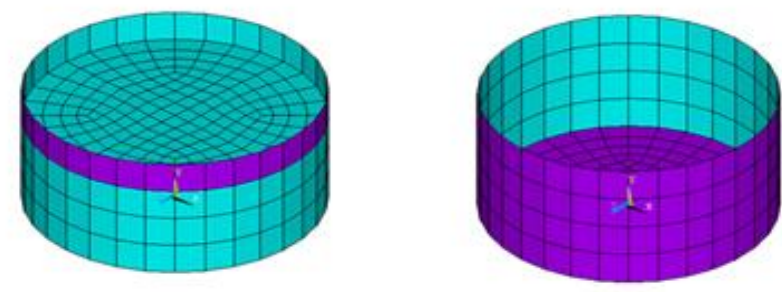

Figure 1. FE modeling of tank No.1 in empty and full condition 


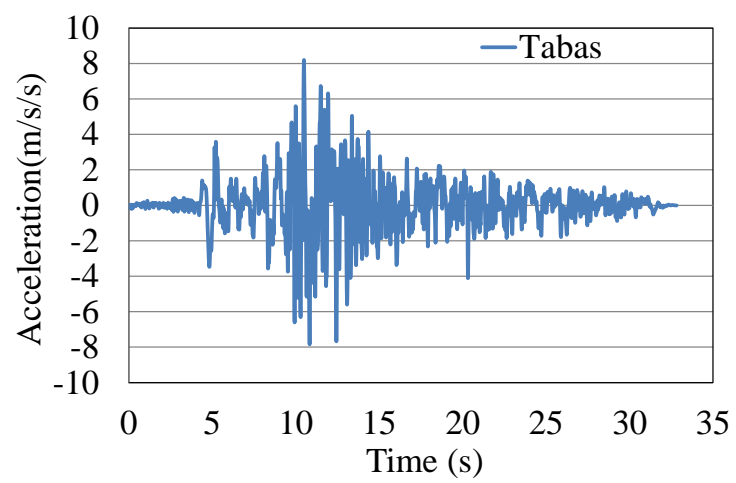

(a)

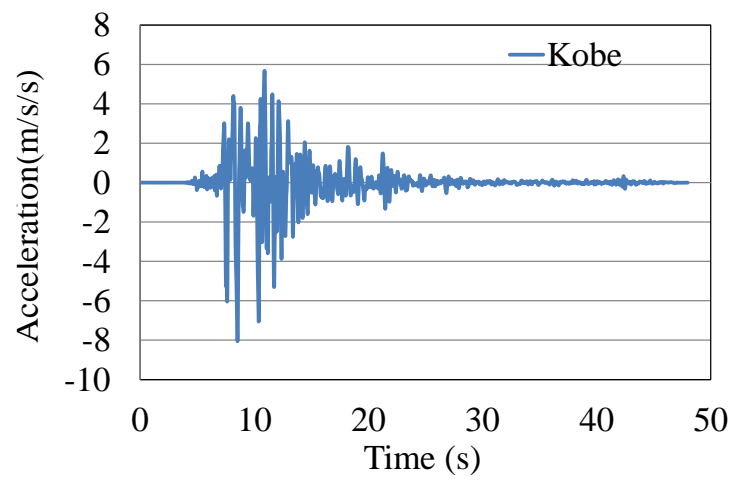

(b)

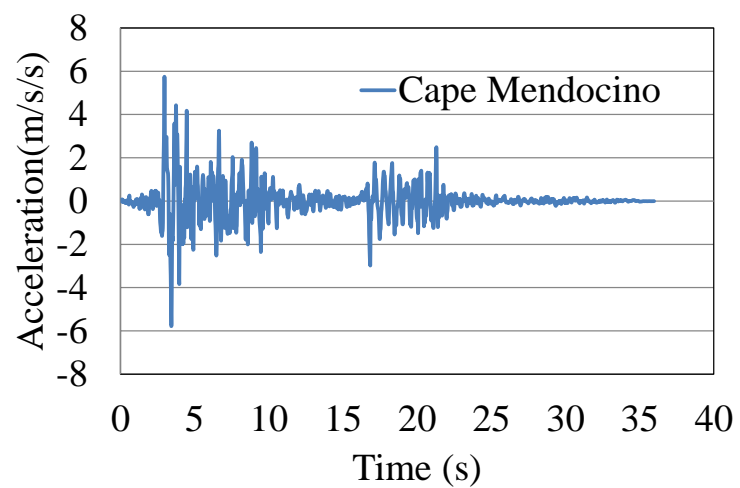

(c)

Figure 2. Horizontal component records of: (a) Tabas; (b) Kobe; (c) Cape Mendocino

\subsection{Modal Analysis and Validation}

Modal parameters including natural frequency, mode shapes, participation factors, modal coefficients, and mass distribution were obtained from modal analyses. Convective and impulsive modes are the most significant frequencies which have the maximum effective mass to account for the dynamic analysis. In addition, this analysis can be a starting point for other analysis, such as response spectrum analysis or time history analysis. Figure 4 shows two vibrational mode shapes of the tank No.1. Table 4 and 5 demonstrates the accuracy and validity of the FE software result. In Table 4, the natural frequencies and convective and impulsive weights are compared with the analytical solutions calculated by API standard [30]. It can be seen that both natural frequencies and weights obtained from FE method are in good 
agreement with API standard. Also, another verification method is shown in Table 5. To this end, some structural responses of an analytical model that was proposed in Ozdemir et al [31] are compared with those obtained from current FE method. The tank model used in the Ozdemir et al. research, has a radius of $1.83 \mathrm{~m}$ and a total height of $1.83 \mathrm{~m}$. Tank is filled up to a height $1.53 \mathrm{~m}$ water with a density of 1000 $\mathrm{kg} / \mathrm{m}^{3}$. The tanks shell was assumed to be aluminum with a density of $2700 \mathrm{~kg} / \mathrm{m}^{3}$, elastic modulus of $71.0 \mathrm{GPa}$ and yield stress of $100 \mathrm{MPa}$. In the numerical analysis, the horizontal component of the El Centro 1940 earthquake with $0.50 \mathrm{~g}$ peak acceleration was used. In addition, API 650 presented some vital equations to find an exact amount of convective and impulsive frequencies. These are universally accepted as common relations in order to find these frequencies. Eqs $(1,2)$ are the most fundamental when it comes to convective frequency.

$$
\begin{aligned}
& T_{c}=1.8 K_{s} \sqrt{D} \\
& K_{s}=\frac{0.578}{\sqrt{\tanh \left(\frac{3.68 H}{D}\right)}}
\end{aligned}
$$

Where $T_{c}$ is the natural period of the convective mode (s), D is nominal tank diameter (m) and $\mathrm{H}$ is maximum design product level $(\mathrm{m})$ and $K_{s}$ is sloshing factor. Moreover, a simplified method was presented in the API to determine the impulsive period.

$$
T_{i}=\left(\frac{1}{\sqrt{2000}}\right)\left(\frac{C_{i} H}{\sqrt{\frac{t_{u}}{D}}}\right)\left(\frac{\sqrt{\rho}}{\sqrt{E}}\right)
$$

In which, $T_{i}$ is impulsive period, $C_{i}$ is a coefficient for determining of impulsive period and can be obtained from Figure 3, $t_{u}$ is the wall thickness, $\rho$ is density and $E$ is elasticity module. API has suggested values of $C_{i}$ and $C_{c}$ as a following Figure 3.

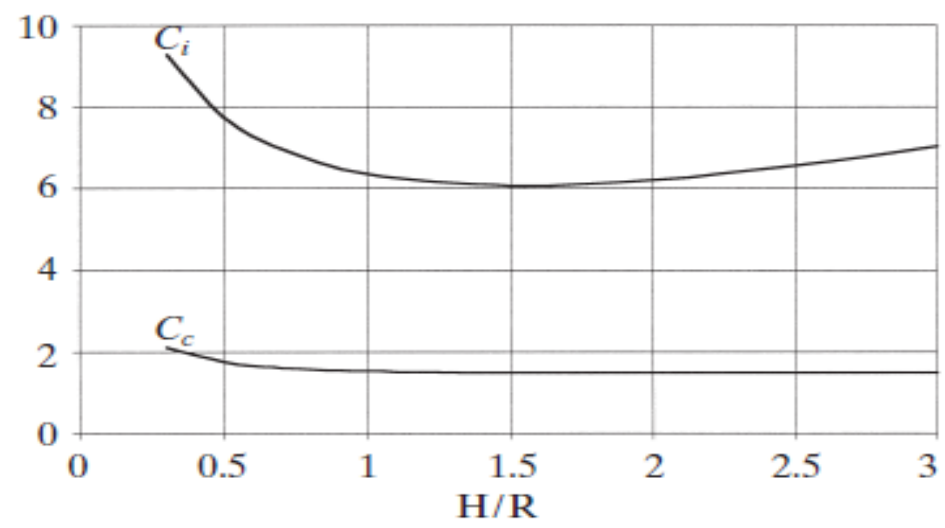

Figure 3. Impulsive and convective coefficients [32] 
Yazdanian et al. / Anadolu Univ. J. of Sci. and Technology A-Appl. Sci. and Eng. 18 (2) - 2017

Table 4. Natural frequencies of CSTs (Hz) and convective and impulsive weights of CSTs (Ton)

\begin{tabular}{ccccccccc}
\hline $\begin{array}{c}\text { Tank } \\
\text { No }\end{array}$ & $\begin{array}{c}\text { Convective } \\
\text { mode } \\
\text { (FEM) }\end{array}$ & $\begin{array}{c}\text { Convective } \\
\text { mode } \\
\text { (API) }\end{array}$ & $\begin{array}{c}\text { Impulsive } \\
\text { mode } \\
\text { (FEM) }\end{array}$ & $\begin{array}{c}\text { Impulsive } \\
\text { mode } \\
\text { (API) }\end{array}$ & $\begin{array}{c}\text { Convective } \\
\text { weight } \\
\text { (FEM) }\end{array}$ & $\begin{array}{c}\text { Convective } \\
\text { weight } \\
\text { (API) }\end{array}$ & $\begin{array}{c}\text { Impulsive } \\
\text { weight } \\
\text { (FEM) }\end{array}$ & $\begin{array}{c}\text { Impulsive } \\
\text { weight } \\
\text { (API) }\end{array}$ \\
\hline 1 & 0.25 & 0.26 & 19.8 & 19.4 & 267.6 & 272.9 & 215.3 & 211.7 \\
\hline 2 & 0.27 & 0.27 & 12.54 & 12.7 & 279.2 & 286.4 & 562.5 & 558.4 \\
\hline 3 & 0.27 & 0.27 & 9.26 & 9.24 & 331.5 & 339 & 854.5 & 850 \\
\hline 4 & 0.3 & 0.31 & 9.97 & 9.99 & 168.1 & 174.4 & 889.6 & 885.5 \\
\hline 5 & 0.37 & 0.38 & 10.44 & 10.36 & 36.4 & 38 & 257.4 & 253.2 \\
\hline
\end{tabular}

Table 5. Structural response of the tank model (units: N, m)

\begin{tabular}{lccc}
\hline \multicolumn{1}{c}{ Parameter } & Ozdemir et al. & $\begin{array}{c}\text { Current } \\
\text { research }\end{array}$ & API \\
\hline Max sloshing wave height & 0.09 & 0.09 & 0.16 \\
\hline Base shear & $4.62 \times 10^{4}$ & $4.61 \times 10^{4}$ & $3.87 \times 10^{4}$ \\
\hline
\end{tabular}
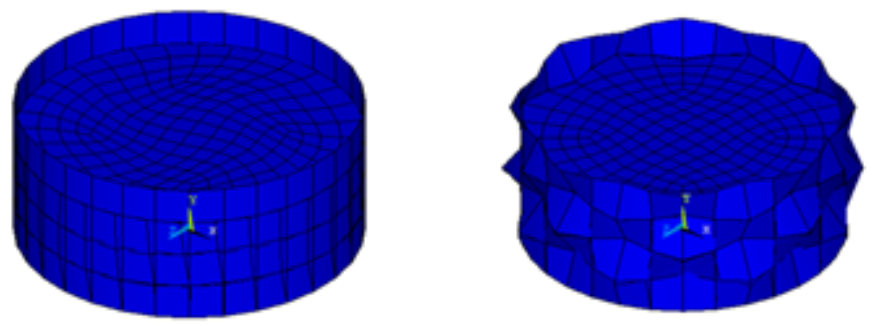

Figure 4. Mode shape of tank No. 1 under modal analysis

\subsection{Results Summary}

A summary of the main results of static and response spectrum analysis is presented in Table 6 and 7 respectively. Two tanks (No. 1 and No. 5) have the lowest displacement and tensile stress in both static and response spectrum analysis. These two tanks have less fluid volume than the other three tanks and thus, tolerated less displacement and tensile stress. Tank No. 3, with the highest volume of fluid among other tanks, has the highest displacement and tensile stress. This is because of the fact that volume of stored liquid in this tank is higher than the other four tanks. It should be noted that the maximum displacement is the highest value in all three directions. In tank No. 1, the maximum tensile stress occurred at the height of 1.5 meter which is shown in Figure 5, while in other cases the maximum stress occurred at a height of 1.5 to 3 meters. On the case of wave height in tanks which is presented in Table 7 and 8, it is clear that the highest wave height is obtained for tanks No. 1, No. 2 and No. 3. This is due to having greater diameters of these tanks than the other two tanks. This was observed for both time history and response spectrum analyses. Figure 6 shows the wave height of tank No. 1 along response spectrum analysis. Displacements values obtained from time history analysis are shown in Table 8; it can be seen that the highest displacement is obtained for the Tabas record. Looking at this table also makes it clear that the highest and lowest displacements occurred in tanks No.3 and No.1 respectively. Although tanks No.1 has a slightly higher value of wave height, the tank No.3 witnessed much more displacements. The most convincing reason in regard to this is because of the fact that the volume of stored liquid in tank with $\frac{H}{D}=1$ is higher than tanks with $\frac{H}{D}=0.5$. Another interesting point is that wave height values obtained from time history analysis is higher those obtained from response spectrum analysis. This suggests that time history analysis is more crucial than response spectrum analysis. Furthermore, the Tabas earthquake has a higher PGA and this contributing to higher wave heights in the 
results. Maximum wave height in three tanks with $\frac{H}{D}=0.5$ are higher than the other $\frac{H}{D}=1$ and $\frac{H}{D}=0.8$, two tanks. These three tanks have greater diameter and as a result present higher values of sloshing. This was previously discussed in response spectrum analysis. Also, a comparison of results show that, there is a huge difference between the results obtained from time history analysis and response spectrum analysis and this difference is due to the fact that acceleration magnitude of earthquakes which have been selected for time history analysis, are higher than spectrum which was calculated from codes in response spectrum analysis. In the time history analysis, the tanks are excited using a realistic ground motion record, whereas in response spectrum analysis the tanks are excited by a spectrum which is calculated from codes. However, it is worthwhile to note that most of the seismic codes consider response spectrum analyses as being one of the dynamic analysis methods in designing and assessing the structures.

Table 6. Comparison of the results obtained from static analysis

\begin{tabular}{crrr}
\hline Tank No & $\frac{H}{D}$ & $\begin{array}{c}\text { Maximum displacement } \\
(\mathrm{m})\end{array}$ & \multicolumn{2}{c}{$\begin{array}{c}\text { Maximum tensile stress } \\
(\mathrm{MPa})\end{array}$} \\
\hline 1 & 0.5 & 0.0009 & 16 \\
\hline 2 & 0.8 & 0.0014 & 32.3 \\
\hline 3 & 1 & 0.002 & 49.4 \\
\hline 4 & 1.25 & 0.0014 & 38.8 \\
\hline 5 & 2 & 0.0006 & 23.1 \\
\hline
\end{tabular}

Table 7. Comparison of the results obtained from response spectrum analysis

\begin{tabular}{lrrrr}
\hline $\begin{array}{l}\text { Tank } \\
\text { No }\end{array}$ & $\frac{H}{D}$ & $\begin{array}{c}\text { Maximum } \\
\text { displacement (m) }\end{array}$ & $\begin{array}{c}\text { Maximum } \\
\text { tensile stress } \\
(\mathbf{M P a})\end{array}$ & Wave height (m) \\
\hline 1 & 0.5 & 0.0009 & 17.2 & 0.502 \\
\hline 2 & 0.8 & 0.0015 & 33.2 & 0.528 \\
\hline 3 & 1 & 0.003 & 68.6 & 0.524 \\
\hline 4 & 1.25 & 0.0018 & 46.1 & 0.449 \\
\hline 5 & 2 & 0.0018 & 26.6 & 0.319 \\
\hline
\end{tabular}

Table 8. The maximum displacement and wave height obtained from time history

\begin{tabular}{|c|c|c|c|c|c|}
\hline Earthquake name & $\frac{H}{D}$ & $\begin{array}{l}\text { Longitude } \\
\text { displacement } \\
(\mathbf{m})\end{array}$ & $\begin{array}{c}\text { Vertical } \\
\text { displacement } \\
(\mathbf{m})\end{array}$ & $\begin{array}{c}\text { Transverse } \\
\text { displacement } \\
(\mathbf{m})\end{array}$ & $\begin{array}{l}\text { Wave height } \\
\text { (m) }\end{array}$ \\
\hline Tabas & \multirow{3}{*}{0.5} & 0.0037 & 0.0005 & 0.0001 & 2.42 \\
\hline Kobe & & 0.001 & 0.0002 & 0.00009 & 1.24 \\
\hline Cape Mendocino & & 0.001 & 0.0002 & 0.00008 & 1.12 \\
\hline Tabas & \multirow{3}{*}{0.8} & 0.012 & 0.002 & 0.0005 & 1.9 \\
\hline Kobe & & 0.005 & 0.001 & 0.0003 & 0.929 \\
\hline Cape Mendocino & & 0.004 & 0.001 & 0.0002 & 0.865 \\
\hline Tabas & \multirow{3}{*}{1} & 0.089 & 0.677 & 0.166 & 2.41 \\
\hline Kobe & & 0.041 & 0.162 & 0.056 & 0.975 \\
\hline Cape Mendocino & & 0.029 & 0.131 & 0.05 & .97 \\
\hline Tabas & \multirow{3}{*}{1.25} & 0.019 & 0.005 & 0.001 & 2.048 \\
\hline Kobe & & 0.009 & 0.002 & 0.0006 & 0.95 \\
\hline Cape Mendocino & & 0.009 & 0.003 & 0.0008 & 0.91 \\
\hline Tabas & \multirow{3}{*}{2} & 0.01 & 0.005 & 0.001 & 1.864 \\
\hline Kobe & & 0.008 & 0.003 & 0.0005 & 0.861 \\
\hline Cape Mendocino & & 0.005 & 0.004 & 0.0008 & 0.827 \\
\hline
\end{tabular}




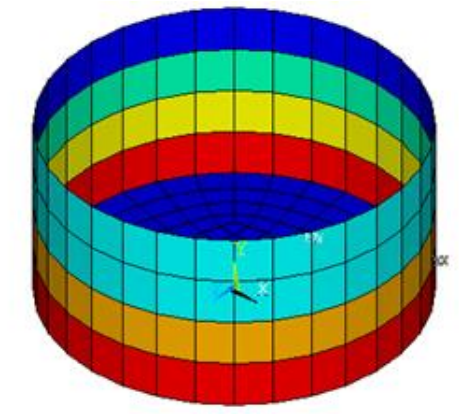

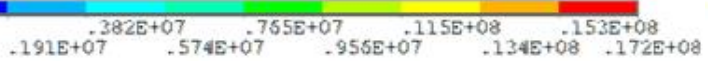
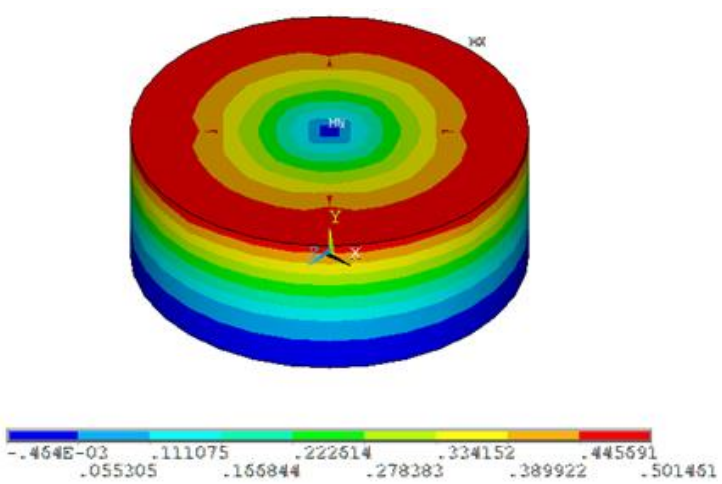

Figure 5. Maximum tensile stress in No. 1 tank wall

Figure 6. Maximum wave height in No. 1 tank

\subsection{Criterions Vulnerability of Storage Tank}

Different parameters can be crucial for the performance of tanks during an earthquake. Posed stresses along the tank body may lead to elephant-foot buckling. Furthermore, waves created by an earthquake and sloshing of liquid in tanks could lead to significant damage to the roof of the tanks. In addition, base shears can overcome the base friction causing the tank to slide. Base uplifting can cause several damages such as damage the piping connected to the tank that are incapable of accommodating large vertical displacements, rupture the base plate-mantle junction due to excessive joint stresses, and uneven settlement of the foundation [14]. With a more detailed look at the past earthquakes, it can be seen clearly that some tanks have been damaged along severe earthquakes. Three parameters are the most crucial matter on the cause of these defections. Theses failures are in three modes which are sliding, Elasto-Plastic buckling (Elephant foot buckling), and tank roof damage. These three parameters are investigated using the two significant API and ASCE standards [33] which proposed some formulations to predict whether a tank will be in danger during an earthquake or not.

\subsubsection{Elephant-fooot buckling}

This parameter is generally a problem for tanks with large diameters. In fact, elephant- foot buckling is an outward bulge just above the base of the tank. Although, it can be created in every place, it can be seen more often at the lowest part of the tanks. A further explanation can be seen in Figure 7 that was taken by Brunesi et. al [13]. This Elephant-foot buckling occurred between heights of 1.5 to 2.5 meter of present tanks. For evaluation of this criteria, both static and response spectrum analysis are used. According to the ASCE [33], the highest amount of stress, $\mathrm{F}_{\mathrm{a}}$ should be limited to the following equation.

$$
\mathrm{F}_{\mathrm{a}}=1.6(0.6 \mathrm{Fy})
$$

Where, $F_{y}$ is yield stress of tanks shell. In the current study, according to the case studies and data, this is assumed to be $23.5 \times 10^{10} \mathrm{MPa}$. It should be noted that this equation mandate users to utilize both static and response spectrum analysis. Table 9 reveals that all the tanks show quite appropriate performances along the investigation of tanks under this parameter. It should be noted that this type of behavior is quite predictable, since the diameter of tanks is less than 25 meter. According to the author's investigation, this diameter is a limit which Elephant-foot buckling usually occurs. It is worthwhile to note that this viewpoint was previously indicated by Hosseinzadeh et al [14]. However, looking at the present constructed cylindrical tanks in industrial plants even with this low diameters (lower than 25), it can be seen that there is a slight Elephant-foot buckling but this is not more than allowance value. 


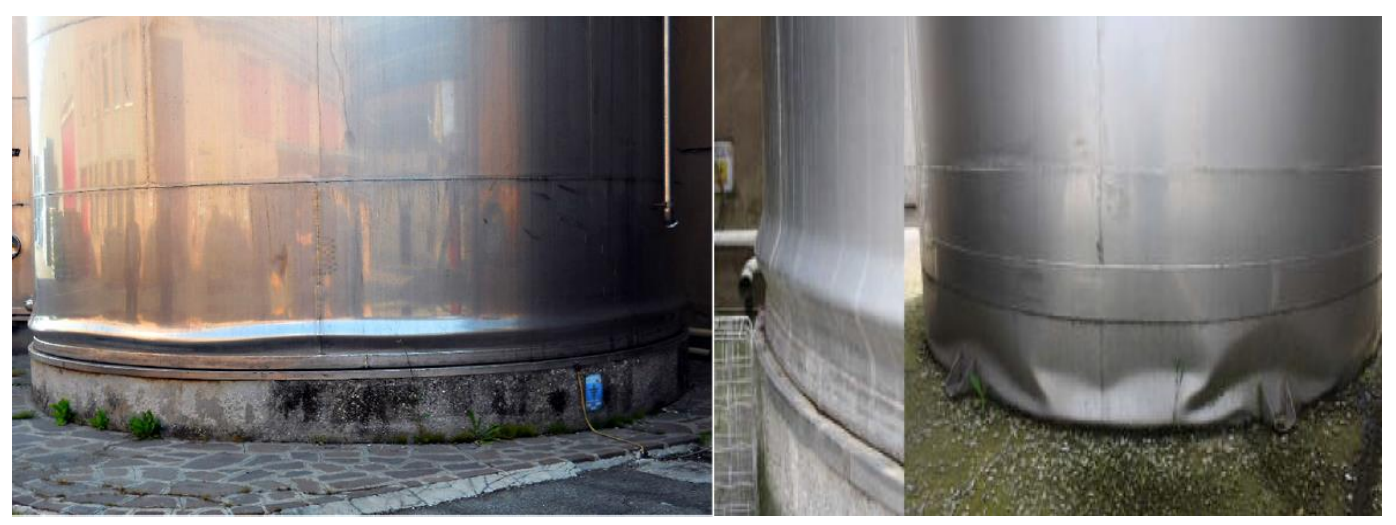

Figure 7. Elephant's foot buckling, Emilia earthquake, Italy, 20 and 29 May 2012 [13]

Table 9. Control of elephant-foot buckling

\begin{tabular}{crrrr}
\hline $\begin{array}{c}\text { Tank } \\
\text { No }\end{array}$ & $\frac{H}{D}$ & $\begin{array}{c}\text { Allowance } \\
\text { value } \\
\text { (MPa) }\end{array}$ & $\begin{array}{c}\text { Maximum tensile } \\
\text { stress (MPa) }\end{array}$ & $\begin{array}{c}\text { Vulnerability } \\
\text { condition }\end{array}$ \\
\hline 1 & 0.5 & 226 & 17.2 & Ok \\
\hline 2 & 0.8 & 226 & 33.2 & Ok \\
\hline 3 & 1 & 226 & 68.6 & Ok \\
\hline 4 & 1.25 & 226 & 46.1 & Ok \\
\hline 5 & 2 & 226 & 26.6 & Ok \\
\hline
\end{tabular}

\subsubsection{Evaluation of tank's roof vulnerability}

Motion of liquid in a tank usually occurs during a severe earthquake. Recent earthquakes have revealed that it is quite possible that the level of wave height reach to several meters. It is completely obvious that the roof would be under damage in such conditions. It can also be predicted that this occurrence is occurred at the joints between the walls and the ribs of the roof which are usually frangible, leading to overflow of tank contents over the top of the tank. Practically to address this issue, an adequate freeboard could be an effective solution. In other words, providing freeboard should be sufficient according to the calculated height of the wave's height created by an earthquake. This occurrence is more highlighted if the liquids are toxic or if spilling could cause damage to piping or scouring of the foundation. However, there are some possible solution including damping methods against sloshing, e.g., grillages or vertical slender walls may be utilized to decline wave height.

It has been proved that tank diameter (D) and the fundamental period of convective mode $\left(T_{c}\right)$ are dominant factors for evaluation of fluid sloshing [34]. It should be noted that the convective frequencies are much less than impulsive frequencies. According to API (2008) standard, freeboard should be at least 70 percent of wave height created along an earthquake. It is evident from Table 10 that tanks No. 2, 4 and 5 show a good performance when it comes to this mode of failure. However, tanks No. 1 and 3 which have higher diameters compared to the other tanks, show a vulnerability behavior against this mode of fragility. 
Table 10. Control of tank's roof vulnerability

\begin{tabular}{crrccc}
\hline $\begin{array}{c}\text { Tank } \\
\text { No }\end{array}$ & $\frac{H}{D}$ & Wave height & $\begin{array}{c}\text { Current } \\
\text { freeboard }\end{array}$ & $\begin{array}{c}\text { Minimum } \\
\text { required } \\
\text { freeboard }\end{array}$ & $\begin{array}{c}\text { Vulnerability } \\
\text { condition }\end{array}$ \\
\hline 1 & 0.5 & 2.42 & 1.5 & 1.69 & Not Ok \\
\hline 2 & 0.8 & 1.9 & 1.5 & 1.33 & Ok \\
\hline 3 & 1 & 2.41 & 1.5 & 1.68 & Not Ok \\
\hline 4 & 1.25 & 2.048 & 1.5 & 1.43 & Ok \\
\hline 5 & 2 & 1.864 & 1.5 & 1.3 & Ok \\
\hline
\end{tabular}

\subsubsection{Control of sliding}

In general, sliding of the tank should be prevented during a seismic event. The resisting shear force at the interface of the base of the structure and the foundation shall be evaluated taking into account the effects of the vertical component of the seismic action.

For the evaluation of the sliding resistance, the transfer of the total lateral shear force between the tank and the subgrade shall be considered. In order to control sliding, the maximum base shear is obtained through both response spectrum and time history analysis. There is a force against the sliding which can be obtained using combination of friction and tank's weight. According to ASCE [33], considered safety factor against the sliding should be equal to 1.5. In addition, friction coefficient between the bottom of tank and foundation should be assumed to 0.4 . Hence, to control the sliding for cylindrical tanks, the following equation should be considered.

$$
0.4 \mathrm{~W}>1.5 \mathrm{~V}
$$

Where, $\mathrm{W}$ is the weight of tank (liquid and tank's shell) and V is the maximum base shear. It should be noted that both $\mathrm{W}$ and $\mathrm{V}$ are in unit of MN. Results related to the sliding's control are shown in the Table 11. It can be observed that tank No.1 shows a good performance against this mode of fragility. The most important reason why this tank has an appropriate performance is because of the fact that this tank has a large diameter and a low height. It has been proven that tanks that have a low ratio of H/D have a low possibility of vulnerability against the sliding.

Table 11. Sliding control for studied tanks

\begin{tabular}{crrrrr}
\hline $\begin{array}{c}\text { Tank } \\
\text { No }\end{array}$ & $\frac{H}{D}$ & $\begin{array}{c}\text { Base shear }(\mathbf{M N}) \\
\mathbf{1 . 5 V}\end{array}$ & $\begin{array}{c}\text { Resistant force }(\mathbf{M N}) \\
\mathbf{0 . 4 W}\end{array}$ & $\begin{array}{c}\text { Ratio } \\
(\mathbf{1 . 5 V}) /(\mathbf{0 . 4 W})\end{array}$ & $\begin{array}{c}\text { Vulnerability } \\
\text { condition }\end{array}$ \\
\hline 1 & 0.5 & 1.776 & 2.098 & 1.181 & Ok \\
\hline 2 & 0.8 & 5.229 & 3.460 & 0.660 & Not Ok \\
\hline 3 & 1 & 13.85 & 4.830 & 0.348 & Not Ok \\
\hline 4 & 1.25 & 7.559 & 3.112 & 0.412 & Not Ok \\
\hline 5 & 2 & 3.309 & 1.216 & 0.367 & Not Ok \\
\hline
\end{tabular}

\section{CONCLUSION}

In this paper five tanks were first modelled by a FE software. All these tanks had different dimensions. Then a comprehensive study has been conducted on these tanks in order to evaluate the seismic vulnerability of these tanks. According to seismic vulnerability analysis by using FEM and linear and non-linear static and dynamic analysis, the most noticeable results are as follows: 
1. Comparison of static and response spectrum showed that, by 130 percent increase in tanks volume ratio, there will be a corresponding 208 and 298 percent increase in the tensile stress for static and response spectrum analyses, respectively. This is due to the fact in static analysis tanks are not excited by any type of load and in other words, they are just under their weight. Conversely, in response spectrum analysis, tanks should be show a performance under a spectrum which is compounded to the static loads.

2. Another remarkable result is that 23 percent increase in volume leads to stresses value decline by 17 percent in static and 28 percent in response spectrum analyses, which was due to the 56 percent rise in (H/D). In addition, a stark distinction between static analysis and response spectrum was observed, where, the values of stress and displacement witnessed a significant 16.6 and 57.14 percent growth from static to response spectrum analysis.

2. Evaluation of Elephant-foot buckling mode showed that all the tanks are quite safe along the investigation of tanks under this fracture mode. However, it was shown that increase in volume of stored liquid leads to a rise in Elephant-foot buckling possibility.

3. Studies on the wave height showed that three of five tanks are safe under this fragility parameter, while the other two tanks are vulnerable along the same earthquake. A more detailed look reveals that tanks with higher diameter has witnessed more wave height. This is because of the fact that liquid in tanks with higher diameter have a more space for sloshing.

4. Evaluation of sliding for the modelled tanks showed that just one of the tanks is invulnerable along the earthquake and the four other tanks are quite in danger. It is clear that tanks with higher height to diameter ratio have more in danger of sliding. It suggest that there is a direct relation between this ratio with danger of sliding

\section{REFERENCES}

[1] Bayraktar A, Sevim B, Altunışık A, Türker, T. Effect of the model updating on the earthquake behavior of steel storage tanks. Journal of Constructional Steel Research, 2010; 66, pp. 462-469.

[2] Shekari M, Khaji N, Ahmadi M. On the seismic behavior of cylindrical base-isolated liquid storage tanks excited by long-period ground motions. Journal of Soil Dynamics and Earthquake Engineering, 2010; 30, pp. 968-980.

[3] Akatsuka H, and Hideo K. Fire of petroleum tank, etc. by Niigata earthquake, 2008.

[4] Yazdanian M, Razavi SV, Mashal M.. Study on the dynamic behavior of cylindrical steel liquid storage tanks using finite element method. Journal of Theoretical and Applied Vibration and Acoustics 2016; 2(2):144-165.

[5] Housner GW. The dynamic behavior of water tanks. Journal of Bulletin of the Seismological Society of America, 1963; 53, pp. 381-7.

[6] Edwards N. A procedure for the dynamic analysis of thin walled cylindrical liquid storage tanks. Ph.D. thesis. Ann Arbor (MI): University of Michigan, USA, (1969).

[7] James RW, Raba WG. Behavior of Welded steel water-storage tank. Journal of Structural Engineering, (1991). 
[8] Brown KJ, Rugar PJ, Davis CA, Rulla TA. Seismic performance of Los Angeles water tanks. Proc. Fourth U.S. Conf. On Lifeline Earthquake Engrg., M. J. O'Rourke, Editor, ASCE, New York, NY, 668675, 1995.

[9] Haroun MA. Behaviour of unanchored oil storage tanks: imperial valley earthquake. Journal of Technical Topics in Civil Engineering; 1983; 109(1):23-40.

[10] Gupta RK, Hutchinson GL. Effects of wall flexibility on the time response of liquid storage tanks. Engineering Structures, 1991; 13:253-67.

[11] Kieselbach R. Bursting of a silo. Engineering Failure Analysis, 1997; 1(4), 49e55.

[12] Dogangun A, Karaca Z, Durmus A, Sezen H. Cause of damage and failures in silo structures. Journal of Performance of Constructed Facilities, 2009.

[13] Brunesi E, Roberto N, Marco P, Dumitru B. Seismic performance of storage steel tanks during the May 2012 Emilia, Italy, earthquakes. Journal of Performance of Constructed Facilities, 2014; 29, no. 5.

[14] Hosseinzadeh N, Hamid K, Masoud G, Ehsan A, Navid Kazem. Comparison of API650-2008 provisions with FEM analyses for seismic assessment of existing steel oil storage tanks. Journal of Loss Prevention in the Process Industries, 2013; 26, no. 4.

[15] Buratti N, Tavano M. Dynamic buckling and seismic fragility of anchored steel tanks by the added mass method. Earthquake engineering and structural dynamics 2014; 43(1), 1-21.

[16] Colombo JI, Almazán JL. Seismic reliability of continuously supported steel wine storage tanks retrofitted with energy dissipation devices. Engineering Structures 2015; 98, 201-211.

[17] Fischer FD, Rammerstorfer FG. A refined analysis of sloshing effects in seismically excited tanks. International Journal of Pressure Vessels and Piping; 1999; 76(10):693-709.

[18] Zienkiewicz OC, Taylor RL, Nithiarasu P. The finite element method for fluid dynamics. 6th ed, Amsterdam; London: Elsevier Butterworth-Heinemann. xii, 435 p., [6] p. of plates, 2005.

[19] Westergaard HM. Water pressures on dams during earthquakes. Transactions of the American Society of Civil Engineers, 1933; 98:418-433.

[20] Virella JC, Suarez LE, Godoy LA. Effect of pre-stress states on the impulsive modes of vibration of cylindrical tank liquid systems under horizontal motions. Journal of Vibration and Control, 2005; 11(9):1195-1220.

[21] Kianoush MR, Chen JZ. Effect of vertical acceleration on response of concrete rectangular liquid storage tanks. Engineering structures 2006; 28(5), 704-715.

[22] Kianoush MR, Ghaemmaghami AR. The effect of earthquake frequency content on the seismic behavior of concrete rectangular liquid tanks using the finite element method incorporating soilstructure interaction. Engineering Structures 2011; 33(7), 2186-2200.

[23] Moslemi M, Kianoush MR. Parametric study on dynamic behavior of cylindrical ground-supported tanks. Journal of Engineering Structures, 2012; 42, pp. 214-230. 
[24] Kim MK, et al. Seismic analysis of base-isolated liquid storage tanks using the BE-FE-BE coupling technique. Soil Dynamics and Earthquake Engineering 2002; 22(9-12):1151-1158.

[25] Gingold RA, Monaghan JJ. Kernel estimates as a basis for general particle methods in hydrodynamics. Journal of Computational Physics 1982; 46(3):429-453.

[26] Gingold RA, Monaghan JJ. Smoothed particle hydrodynamics - theory and application to nonspherical stars. Monthly Notices of the Royal Astronomical Society 1977; 181:375-389.

[27] ANSYS, Inc. ANSYS Release 12.0 Documentation, USA, 2009.

[28] Iranian code of practice for seismic resistant design of buildings, Standard No. 2800- 84, Building and Housing Research Center.

[29] Chopra AK, Dynamics of structures, theory and applications to earthquake engineering. 2nd Ed, Prentice-Hall, 2000.

[30] API Standard 650. Welded steel tanks for oil storage. 11th ed. American Petroleum Institute,Washington, D.C. USA, 2008.

[31] Ozdemir Z, Souli M., Fahjan YM. Application of nonlinear fluid-structure interaction methods to seismic analysis of anchored and unanchored tanks. Journal of Engineering Structures 2010; 32, pp.40923.

[32] Malhotra PK, Wenk T, Wieland M. Simple procedure for seismic analysis of liquid-storage tanks", Structural Engineering International 2000; 10(3), 197-201.

[33] American Society of Civil Engineers (ASCE). Minimum design loads for buildings and other structures. ASCE, 2010; 7-10, Reston, VA.

[34] Yazdanian M, Razavi SV, Mashal M. Seismic Analysis of Rectangular Concrete Tanks by Considering Fluid and Tank Interaction. Journal of Solid Mechanics 2016; 8.2: 435-445. 